\title{
PRÁTICAS INFORMACIONAIS DE JOVENS E ADULTOS: UMA EXPERIÊNCIA COM ESTUDANTES DO PROEJA
}

\begin{abstract}
Resumo: Este estudo buscou identificar as práticas informacionais de estudantes de um curso técnico integrado ao ensino médio na modalidade de educação de jovens e adultos em uma instituição de Brasília, Distrito Federal, Brasil. As questões buscaram identificar características de acesso e uso da informação com destaque para as tecnologias que costumam ser utilizadas, frequência de uso, local de acesso e a preferência pelas ferramentas de comunicação e busca da informação. A pesquisa apresenta caráter descritivo e natureza mista, cuja técnica de coleta de dados foi a entrevista estruturada com emprego de um questionário. Os resultados indicam o acesso diário à internet para a maioria dos participantes, a preferência pelo smartphone como dispositivo de uso e o correio eletrônico e as redes sociais como principais serviços acessados pela Internet. O Facebook foi apontado como preferência de rede social e o Whatsapp foi o serviço de mensagem instantânea mais consumido. Estes dados, além de permitir a identificação das práticas informacionais dos estudantes, sugerem as ferramentas que podem ser empregadas no planejamento de atividades do curso.
\end{abstract}

Palavras-chave: Ciência da Informação. Curso técnico. Jovens e Adultos. Práticas informacionais. PROEJA.

\author{
Sylvana Karla da Silva de Lemos Santos \\ Instituto Federal de Brasília \\ Doutoranda em Ciência da Informação na \\ Universidade de Brasília. Professora de \\ Informática no Instituto Federal de Brasília \\ sylkarla@gmail.com \\ Ivette Kafure \\ Universidade de Brasília \\ Doutora em Ciência da Informação pela \\ Universidade de Brasília - UnB. Professora \\ na Faculdade de Ciência da Informação da \\ UnB \\ ivettekead@gmail.com
}

\section{INFORMATION PRACTICES FOR YOUTH AND ADULTS: AN EXPERIENCE WITH PROEJA STUDENTS}

\begin{abstract}
This study aimed to identify the informational practices of students of a technical course integrated to high school in the youth and adult education modality in an institution of Brasília, Federal District, Brazil. The questions search to identify characteristics of access and use of information, highlighting the technologies that are commonly used, frequency of use, location of access and preference for the tools of communication and search of information. The research presents descriptive character and mixed nature, whose technique of data collection was the interview structured using a questionnaire. The results indicate the daily internet access for most participants, the preference for the smartphone as a device for use and electronic mail and social networks as the main services accessed through the Internet. Facebook was indicated as a social networking preference, and Whatsapp was the most used instant messaging service. These data, besides allowing the identification of the information practices of the students, suggest the tools that can be used in the planning of course activities.
\end{abstract}

Keywords: Information Science. Technical course. Youth and Adults. Informational practices. PROEJA. 


\section{INTRODUÇÃO}

A educação de jovens e adultos no Brasil recebeu uma atenção diferenciada a partir da criação do Programa Nacional de Integração da Educação Profissional com a Educação Básica na Modalidade de Educação de Jovens e Adultos - PROEJA, instituído por meio do Decreto $n^{\circ}$ 5.840/2006 (BRASIL, 2006). Em seu contexto, esta legislação assegura que os cursos e programas do PROEJA considerem as características dos jovens e adultos atendidos com foco no mercado de trabalho.

O PROEJA tem como público "jovens e adultos que não tiveram a oportunidade de cursar o ensino fundamental e/ou o ensino médio na idade regular e que buscam também uma profissionalização" (MACHADO, 2016, p. 39). Estes indivíduos têm em comum a característica de um afastamento escolar que acarretou na não conclusão da formação escolar. Portanto, não se trata de uma modalidade de educação em que os participantes têm idade superior a 19 anos e foram designados a frequentar turmas muitas vezes estigmatizadas, como “os que não estudaram na idade certa”, mas de uma proposta para concluir o ensino médio e ter uma profissão.

No contexto atual de evolução das Tecnologias da Informação e da Comunicação TIC's, o público de jovens e adultos tem experimentado mudanças com relação às ferramentas e aos modos de busca e acesso à informação. As TIC's podem ser definidas como "o conjunto de atividades e soluções providas por recursos de computação que visam permitir o armazenamento, o acesso e o uso das informações para auxiliar a tomada de decisão" (SOUSA, 2016, p. 19). Em um cenário de constante transição tecnológica, as necessidades destes indivíduos vêm modificando o seu comportamento e, consequentemente, suas práticas enquanto usuários da informação, mostrando-se urgente estudar como ocorre a interação destes com as tecnologias e a sociedade, tendo em vista que a informação se constitui em "um instrumento fundamental tanto para o processo educativo quanto para a produção do conhecimento" (REIS; PEDROSO; CUNHA, 2010, p. 18).

Araújo (2013) relata estudos voltados para os indivíduos que se relacionam com a informação, desenvolvidos sob diferentes perspectivas: abordagem Tradicional ou Positivista que está situada no campo da melhoria de serviços, principalmente no ambiente da biblioteca; abordagem Crítica quando o foco passa a estar relacionado com a identificação dos problemas de acesso à informação, bem como aos sistemas de informação e as desigualdades em termos 
de acesso e uso; abordagem Cognitiva com a mudança para a compreensão da necessidade do usuário, considerada como causa, tendo as ações de busca da informação como efeito; e, mais recentemente, surge a abordagem Social a qual enfatiza o caráter coletivo dos indivíduos informacionais e cujo conceito é evidenciado por Savolainen (2007). O autor considera que o discurso sobre o comportamento da informação baseia-se, principalmente, no caráter cognitivo, enquanto a prática informacional advém das ideias da interação social. Como consequência, tem-se o emprego da terminologia práticas informacionais para denominar os estudos a partir da interação entre o sujeito e a informação (DUARTE; ARAÚJO; PAULA, 2017).

Neste contexto, este relato de experiência parte de uma pesquisa de campo desenvolvida no Instituto Federal de Brasília - IFB, na qual estudantes de duas turmas do curso técnico integrado ao ensino médio em Administração na modalidade PROEJA do Câmpus Gama responderam a um questionário impresso. As indagações buscaram identificar as características de acesso e uso das TIC's, bem como as consequentes práticas informacionais dos estudantes afim de relacioná-las para dar embasamento ao planejamento das aulas da componente curricular Informática, durante o segundo semestre letivo de 2016. A pesquisa está situada no contexto da Ciência da Informação - CI, possui caráter interdisciplinar e foi desenvolvida com os sujeitos informacionais de interesse desta investigação, que são os jovens e adultos.

\section{ESTUDOS DE USUÁRIOS DA INFORMAÇÃO}

Os estudos de usuários são investigações que servem para compreender o que os usuários precisam em termos de informação ou se as suas necessidades de informação estão sendo satisfeitas de forma adequada. Com isso, é possível verificar o comportamento do usuário, ou seja, por que, como e para que usam informação (FIGUEIREDO, 1994). Essa subárea da CI surgiu com a preocupação de compreender como os leitores de biblioteca se comportavam para aperfeiçoar os produtos e serviços oferecidos, bem como desenvolver novos serviços (GANDRA; DUARTE, 2013).

Martín Moreno (2007, p. 130) afirma que um usuário da informação é o indivíduo que "necessita de informação para executar suas atividades". Portanto, segundo essa 
afirmação, todos os seres humanos podem ser tipificados como usuários da informação. $\mathrm{O}$ usuário da informação é aquele que produz e consome informação (CALVA GONZÁLEZ, 2012) e a relevância do estudo de usuários na Ciência da Informação (CI) está, portanto, em conhecer quem é esse indivíduo, quais as suas necessidades de informação, como a utilizam e quais seus comportamentos de busca (KAFURE et al., 2013).

Araújo (2016) destaca a compreensão do processo de comportamento informacional do usuário que começa com uma situação problemática, que o levará à busca pela informação, direcionando-o à recuperação e ao uso da informação. Pensemos, portanto, no espaço digital da Web 2.0, no qual o usuário encontra-se imerso e num constante ciclo de busca, recuperação, acesso e uso da informação, caracterizando as práticas informacionais que surgem no convívio social e no uso de ferramentas tecnológicas.

Villaseñor Rodriguez e Calva González (2017) buscaram analisar o perfil dos usuários do novo milênio, imersos na Internet e que fazem uso das ferramentas da Web 2.0, e destacou algumas características em comum, dentre as quais: a presença de um usuário que vive em ritmo acelerado de vida, com características de indiferença ou incapacidade de aprofundar-se, que busca a mudança ou a inclusão em novas formas de grupos sociais nos quais tem empatia, além do caráter consumista; um usuário que faz parte da chamada "Cultura 2.0", caracterizada, principalmente, por uma nova concepção social do ser humano, com desejo de compartilhar, estar informado e de comunicar-se e que, no entanto, não pratica essas ações de qualquer forma, mas por meio das novas tecnologias da informação que o ajuda a obter o que necessitam [tradução nossa]. Os autores evidenciam que o "Usuário 2.0" não é apenas consumidor da informação, mas também produtor, cujo comportamento é marcado por sempre estar comunicando o que faz ou o que sabe cultivando, dessa forma, a inteligência coletiva e democrática, onde todos podem declarar suas opiniões e compartilhar seus conhecimentos.

Para o século atual, essa mudança nas práticas informacionais é percebida nos usuários para os quais, em grande parte e independente de ocupação, o acesso se dá por meio de um dispositivo tecnológico conectado à Internet. Diversos fatores podem ser destacados para justificar essa transição decorridos mais de 20 anos, em especial, devido às transformações do espaço e do tempo pelo surgimento da "Sociedade em Rede", abordada por Castells (1999). Ademais, toda a revolução tecnológica percebida neste novo século tem favorecido a expansão das formas e dos meios de comunicação e, por conseguinte, a 
mobilidade dos usuários pelo uso de equipamentos, como smartphone e tablet, que se integram pela rede sem fio.

De acordo com a Pesquisa TIC Domicílios, realizada em 2016 e divulgada pelo Comitê Gestor da Internet no Brasil - CGI.Br, foi registrado um aumento na proporção de pessoas que acessam a Internet por meio do celular, em relação ao ano anterior, atingindo 93\% dos participantes da pesquisa. No entanto, houve uma redução de $80 \%$ para $57 \%$ na quantidade de usuários da Internet que utilizam o computador para o mesmo fim (CGI.Br, 2017, p. 137). Estes números retratam o caráter de mobilidade dos usuários, face à mudança na preferência de utilização de dispositivo em substituição a outro, caracterizado pela adoção de novas práticas e ao "deslocamento de mídias jovens" (PASSARELLI; ANGELUCI, 2018, p. 197) que, associadas ao surgimento da Internet, permitem novas alternativas de busca e acesso à informação.

\section{AS TIC's NA EDUCAÇÃO}

De acordo com a concepção de Prensky (2001), a evolução das tecnologias evidenciou o surgimento de grupos de pessoas com singularidades que foram alteradas e vão além do visual, como as roupas, e da forma de comunicação, como as gírias: são os chamados nativos digitais e os imigrantes digitais. De forma resumida, enquanto o primeiro nasceu em uma sociedade na qual o acesso à rede mundial de computadores era frequente e os serviços web assim como tecnologias já estavam sedimentadas, o grupo de imigrantes se viu obrigado a acompanhar esse avanço tecnológico e buscar atualizar-se às novidades do mundo cibernético.

De acordo com Soares (2002), essas mudanças impulsionaram novos sentidos ao letramento dos sujeitos, que envolvem as práticas de leitura e de escrita, passando do meio impresso para o meio digital. Essas transições são também demandadas pelos estudantes, em virtude da presença das TIC's em sala de aula e do seu papel transformador, a partir de práticas digitais, como o uso de lousa digital, projetor digital, computador e do próprio smartphone.

Assim, é neste contexto de transição que está concentrada grande parte do público de jovens e adultos que retorna às salas de aula e experimenta formas de produção de conteúdo diferentes das tradicionais às quais estavam acostumados. 


\section{O PROEJA NO INSTITUTO FEDERAL DE BRASÍLIA}

A oferta de cursos na modalidade PROEJA, em âmbito federal, tem permitido a realização de cursos e programas de formação inicial e continuada e de educação profissional técnica de nível médio. Em 2014, o Câmpus Gama do IFB deu início ao programa com o curso Técnico integrado ao ensino médio em Administração na modalidade PROEJA, abertura de 40 vagas semestrais que busca atender à demanda de formação no eixo Gestão e Negócios (BRASIL, 2016). O curso foi o primeiro na modalidade ofertado pelo IFB, sendo considerado um desafio para o corpo docente que, até então, atuava exclusivamente junto a estudantes dos cursos técnico subsequente e licenciatura. Por isso, com o objetivo de capacitar os professores que iriam atuar neste curso, foi realizada uma formação em nível de aperfeiçoamento, totalizando 120 horas de treinamento que contou com orientações de uma especialista em Educação de Jovens e Adultos.

Desde a abertura da primeira turma do curso, houve um crescimento no número de estudantes matriculados, o que indica que houve uma crescente demanda pela formação na área administrativa. O gráfico 1 mostra a evolução no número de matrículas de 2014 a 2018.

Gráfico 1 - Evolução no número de matrículas no curso Técnico em Administração PROEJA - 2014 a 2018

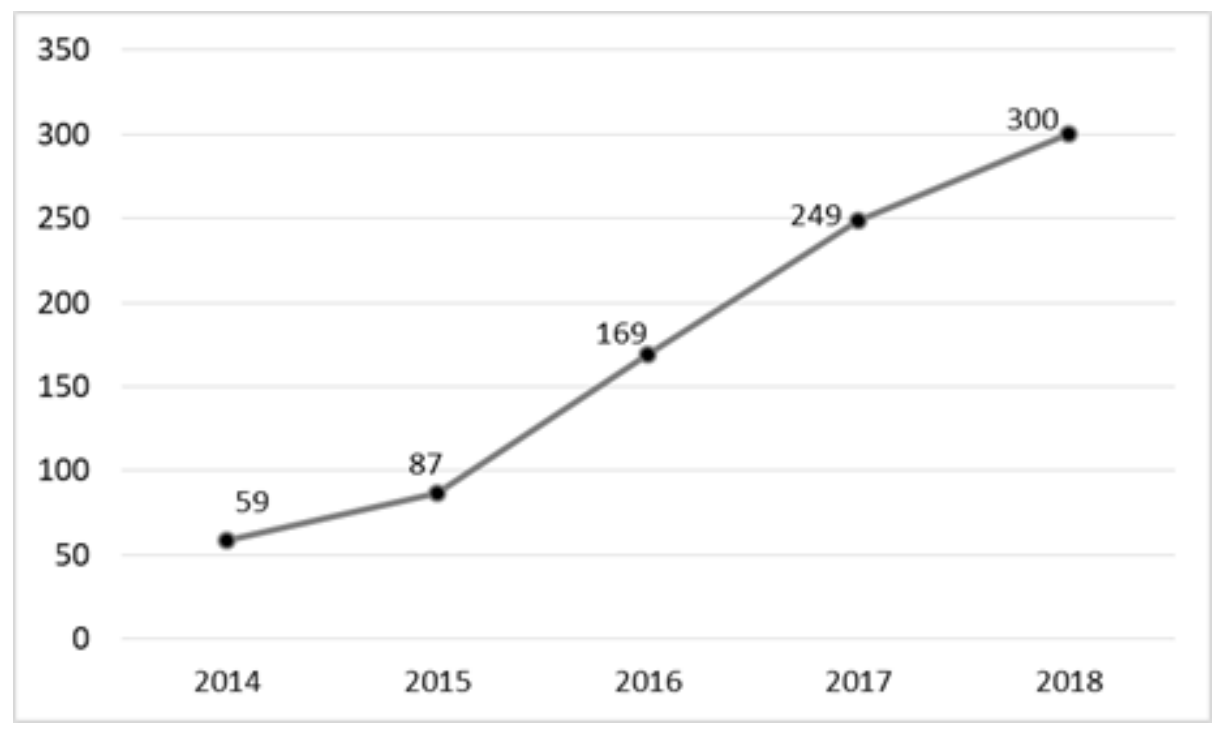

Fonte: Adaptado de IFB em Números - ifbemnumeros.ifb.edu.br (dados de 25 jan. 2019). 
O perfil do profissional que conclui o curso permite que o mesmo execute operações administrativas relativas à organização de protocolos e arquivos, confecção e expedição de documentos e controle de estoques; aplique conceitos e modelos de gestão em funções administrativas e; opere sistemas de informações gerenciais de pessoal e de materiais (BRASIL, 2016). Embora a orientação do curso esteja voltada principalmente para o desenvolvimento de habilidades na área administrativa, a presença das TIC's na otimização das tarefas decorrentes da atuação do técnico em administração mostra ser imprescindível a conexão dos temas teóricos, contidos nas ementas do curso, com o uso de ferramentas e aplicações computacionais a partir do emprego de conceitos de Informática nas tarefas rotineiras de um profissional da área técnica (IFB, 2016). Com esse propósito, a disciplina Informática está presente em três módulos do curso, denominadas: Informática I, Informática II e Informática Aplicada. Essa distribuição visa a aprendizagem gradativa dos estudantes ao longo do curso, de modo que possam associar o conhecimento adquirido com as demais componentes curriculares específicas, principalmente, a partir de projetos integradores que são realizados semestralmente.

Tendo em vista que a docente da disciplina Informática atuou nos dois primeiros módulos durante o segundo semestre de 2016, este relato descreve os dados coletados em duas das disciplinas do curso: Informática I e Informática II. Segundo o plano de curso (IFB, 2016), a disciplina Informática I tem a proposta de abordar temas voltados ao conhecimento e uso do computador, compreensão de software e de hardware, realização de pesquisa utilizando recursos na Internet e comunicação via e-mail; enquanto que a disciplina Informática II está voltada para o desenvolvimento de habilidades de manuseio de aplicativos de escritórios para construção de textos, planilhas e apresentações, além de cuidados básicos para a segurança da informação. Dessa forma, é identificado um leque de temas que podem ser trabalhados durante as aulas e, por isso, busca-se identificar as práticas informacionais que estes estudantes desenvolvem, considerando as experiências positivas e as limitações que possuem com o uso das TIC's. Silva e Marchand (2010) destacam que:

Os computadores, entre outros instrumentos tecnológicos, se fazem presentes junto às escolas da rede pública de ensino, por meio de ambientes informatizados, favorecendo novas possibilidades de comunicação, interação e informação advindas da internet, provocando transformações cada vez mais visíveis em nossa sociedade (SILVA; MARCHAND, 2010, p. 138). 
Algumas pesquisas denotam a preocupação com o uso de ferramentas computacionais na educação de jovens e adultos e podem ser encontradas em publicações recentes voltadas a turmas do IFB. Santos e Rocha (2018) apontaram a necessidade de trabalhar conteúdos na formação técnica que sejam significativos para os estudantes do PROEJA, mediante o planejamento de atividades que possibilitem evidenciar a interdisciplinaridade com temas distintos, como Informática e Língua Portuguesa. A experiência das autoras possibilitou o desenvolvimento de habilidades técnicas, como a elaboração de documentos, segundo orientações de redação oficial, com o auxílio de softwares de edição de texto.

O estudo de Melo e Loureiro (2017) buscou verificar possíveis contribuições do ensino de Informática para a melhoria da autonomia e do senso crítico de estudantes. A investigação considerou um grupo composto por 28 mulheres em situação de vulnerabilidade, matriculadas em um curso de Formação Inicial e Continuada - FIC, na modalidade de Educação de Jovens e Adultos. Os resultados evidenciaram que houve um empoderamento das mulheres por meio da utilização de programas de computador, de modo a auxiliar na busca de informações na Internet e permitir a diferenciação entre fontes confiáveis daquelas suspeitas. Além disso, constatou-se que, para elas, a pesquisa na Internet, que se resumia em "encontrar informação", como um endereço ou uma receita (MELO; LOUREIRO, 2017, p. 192), tomou um novo sentido ao perceberem a facilidade que a Internet proporcionava. Neste sentido, Malheiros e Cunha (2017, p. 153) ressaltam que "um dos meios de inclusão social é o acesso à informação" e destacam sua importância para o desenvolvimento do ser humano.

A seguir, será descrito percurso metodológico que orientou o desenvolvimento da investigação.

\section{PERCURSO METODOLÓGICO}

A pesquisa caracteriza-se como descritiva, uma vez que pretende abordar as peculiaridades de determinada população no contexto em que estão inseridos (KAUARK; MANHÃES; MEDEIROS, 2010). Trata-se de uma pesquisa aplicada, com horizonte temporal que adotou a entrevista como técnica de coleta de dados e o uso de um questionário impresso com questões objetivas como o instrumento de coleta. Apresenta natureza mista, pois 
considera tanto dados quantitativos analisados percentualmente, quanto as respostas descritivas dos participantes. A análise dos dados se deu pela análise do conteúdo das respostas e da comparação com outros estudos relacionados.

A amostra dos participantes é de 50 indivíduos, sendo 38 matriculados em Informática I e 12 matriculados em Informática II, na sua maioria do sexo feminino, possui faixa etária entre 20 e 29 anos, segundo dados do Registro Acadêmico do IFB. A coleta dos dados foi realizada no primeiro dia de aula das disciplinas, cuja carga horária semestral é de 40 horas cada, com encontros semanais de duas horas-aula durante o segundo semestre de 2016. Após a apresentação do plano de ensino de cada disciplina, a docente apresentou o questionário impresso e esclareceu que se tratava de uma "pesquisa diagnóstica", sem necessidade de identificação dos estudantes e com o objetivo de conhecer os "hábitos digitais" e o nível de conhecimento de cada um com relação a temas específicos a serem tratados durante as próximas aulas. Embora aqui estejam sendo relatados os resultados de apenas um semestre, a docente vem realizando coletas semestralmente com as turmas do curso desde 2015. Pontua-se ainda que a escolha pela abordagem dos dados de um semestre específico neste artigo deve-se à possibilidade de investigar uma turma iniciante e outra turma que já estava frequentando o curso há um ano com o propósito é de confrontar as afirmações apresentadas por estes indivíduos em momentos diferentes do curso.

As questões abordaram a posse, o uso e a frequência de uso do computador e do celular para o acesso à internet, além dos principais serviços utilizados, incluindo redes sociais e aplicativos de bate-papo, conhecimento e uso de ferramentas de escritório, totalizando 10 questões objetivas. A última questão, de natureza aberta (subjetiva), procurou investigar os assuntos de interesse dos estudantes da disciplina. O próximo tópico fará uma descrição dos resultados obtidos.

\section{RESULTADOS OBTIDOS}

Para facilitar a explanação dos dados, os estudantes matriculados em Informática I serão denominados de Grupo 1, enquanto que aqueles matriculados em Informática II serão tratados como Grupo 2. Ao serem questionados quanto à posse do computador em casa, a 
resposta foi positiva para 84,2\% do Grupo 1 e 41,7\% do Grupo 2. Quanto à frequência de uso do computador, 39,5\% do Grupo 1 e 41,7\% do Grupo 2 afirma que utilizam diariamente.

Em relação aos dispositivos eletrônicos utilizados para acessar a Internet, observa-se no Grupo 2 a predominância pelo uso do celular ou smartphone (75\%) em relação ao computador (50\%), estando de acordo com os dados da Pesquisa TIC Domicílios 2016 anteriormente apresentados e reflete o caráter de mobilidade destes participantes. Já o Grupo 1 demonstra a preferência pelo uso do computador $(81,6 \%)$ para acessar a Internet, o que pode estar associado à maioria deles possuir este equipamento em casa, bem como pela possível falta de infraestrutura para acesso fora do domicílio (wifi gratuito). Os dados podem ser visualizados por meio do Gráfico 2. Ressalta-se que a resposta para esta questão é de múltipla escolha, de forma que os participantes podem assinalar um ou mais dispositivos simultaneamente.

Gráfico 2 - Dispositivos utilizados para a acessar a Internet, em \%

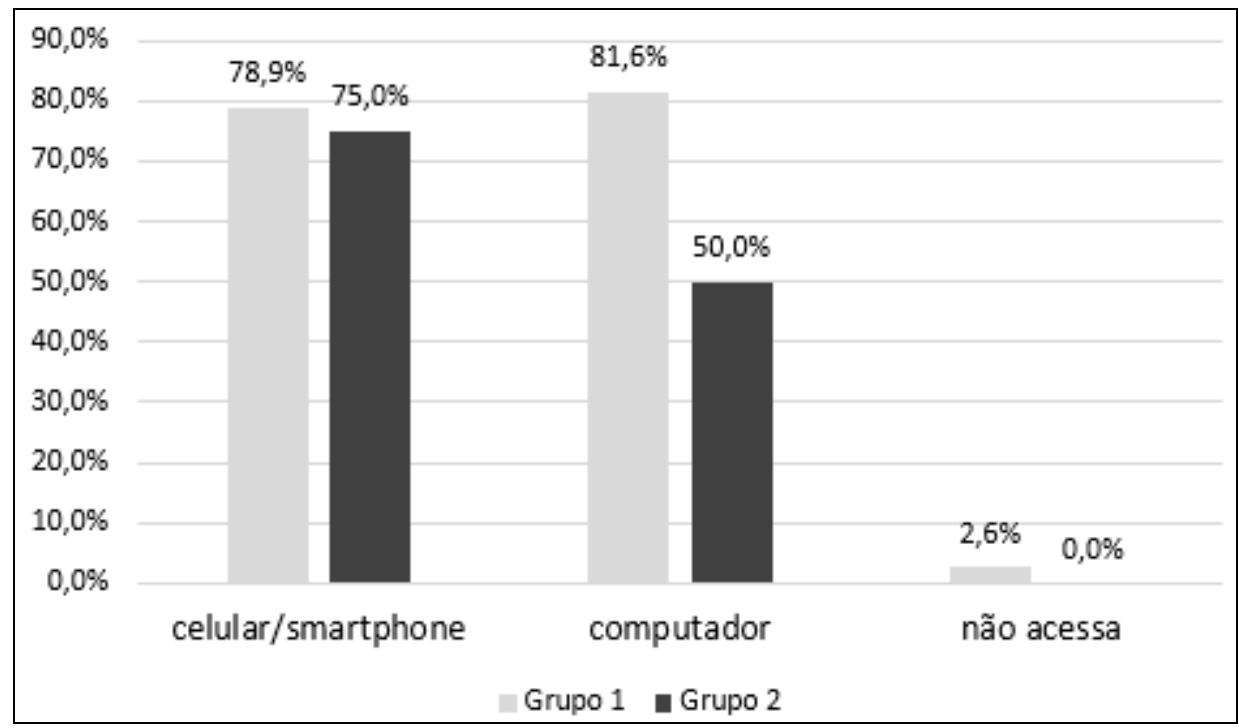

Fonte: Elaborado pelas autoras, 2019.

No tocante à frequência de acesso à Internet pelos participantes, 73,7\% do Grupo $1 \mathrm{e}$ 66,7\% do Grupo 2 afirmam que estão conectados diariamente à rede. Os principais serviços acessados pela Internet estão ilustrados no Gráfico 3 e apontam, principalmente, para o uso de ferramentas de comunicação e de interação social, como o correio eletrônico e as redes sociais, para ambos os grupos alcançando um índice superior a $80 \%$. 
Gráfico 3 - Serviços de Internet mais acessados, em \%

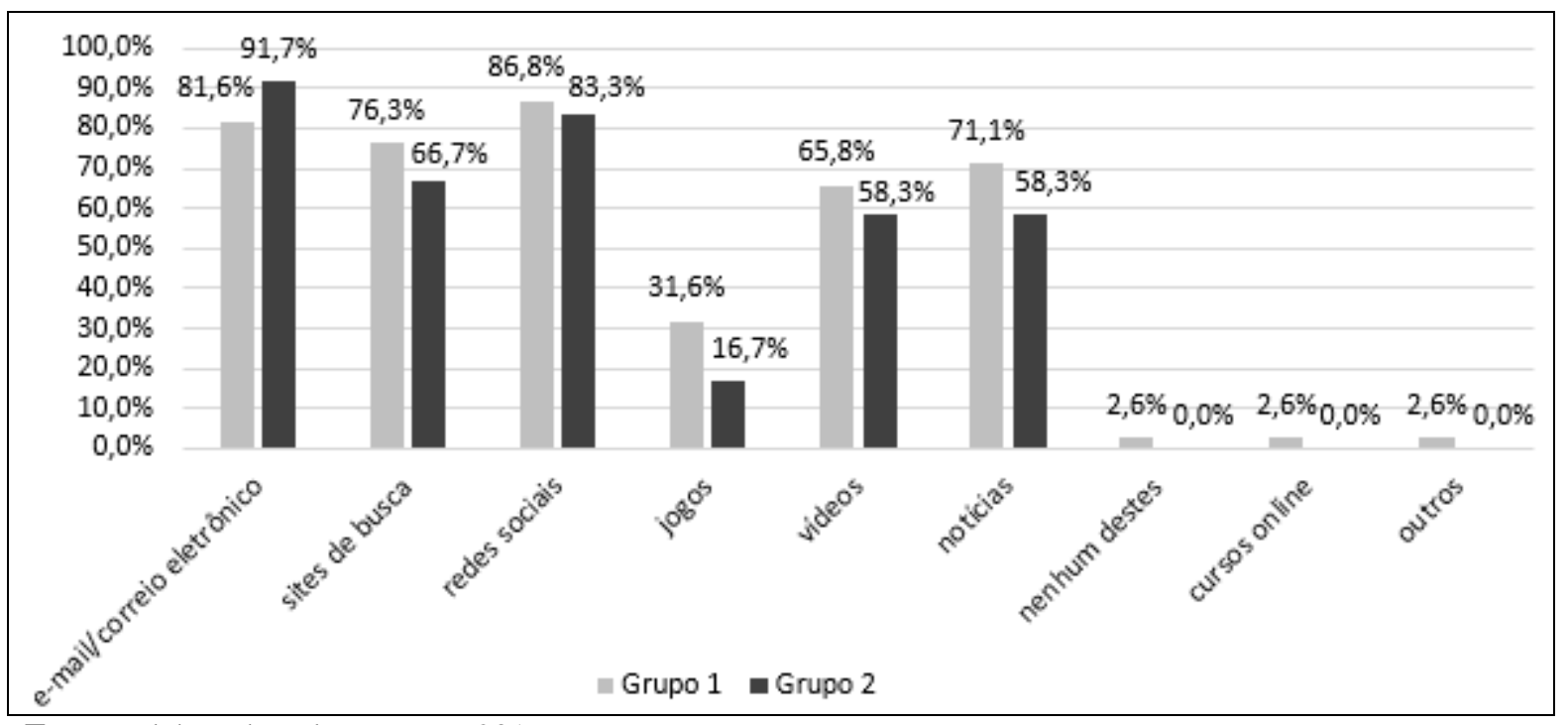

Fonte: Elaborado pelas autoras, 2019.

Os demais índices do Gráfico 3 demonstram, em ordem decrescente, que os dois grupos apresentam características semelhantes ao afirmarem que utilizam sites de busca, pesquisam notícias e assistem vídeos. Esta questão também possui caráter de múltipla escolha, permitindo que os participantes apontem uma ou mais alternativas.

Com relação às redes sociais mais acessadas, o Gráfico 4 apresenta o uso do Facebook, seguido do Instagram e do Twitter para ambos os grupos. O item "outras" não obteve resposta. Tais resultados concordam com aqueles alcançados por Passarelli e Angeluci (2018) que indicaram grande predominância dos participantes por estas redes, dentre outros. Ademais, segundo a pesquisa TIC Domicílios 2016, entre as atividades on-line, as mais mencionadas continuam sendo o uso da Internet para envio de mensagens instantâneas (89\%) e uso de redes sociais $(78 \%)$. 
Gráfico 4 - Redes sociais mais acessadas, em \%

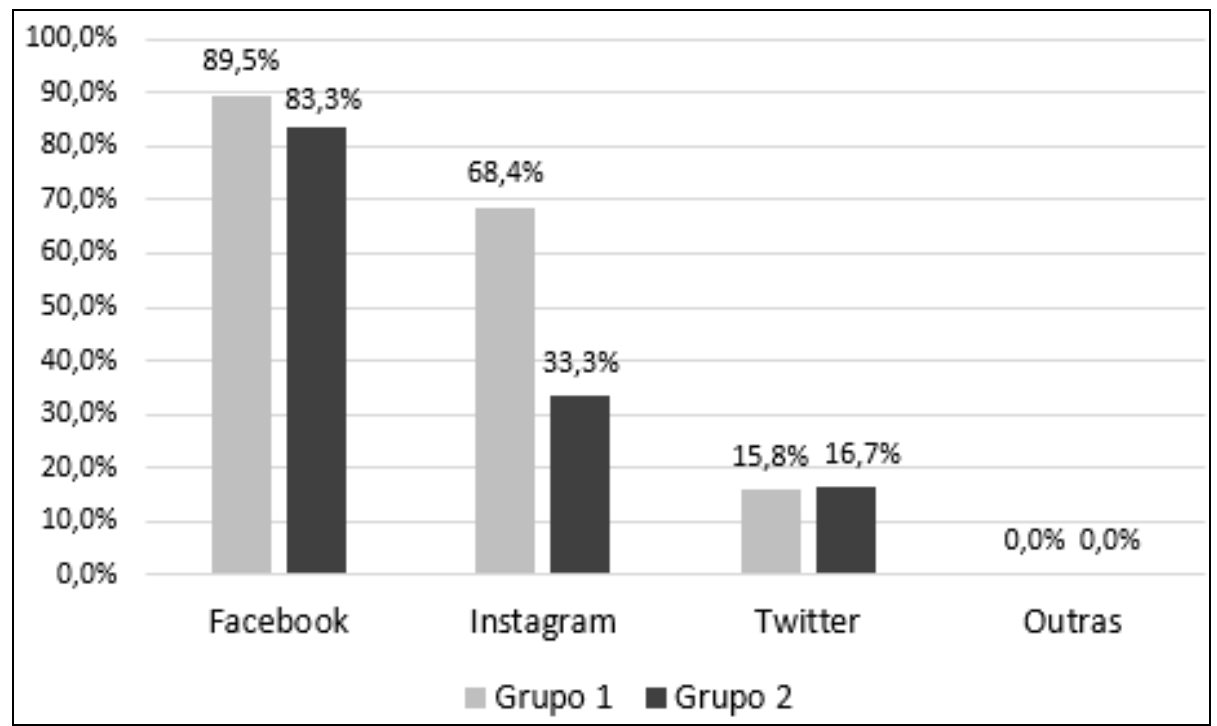

Fonte: Elaborado pelas autoras, data

No contexto do uso de aplicativos de mensagens instantâneas, a pesquisa mostra que a totalidade dos estudantes (100\%) em cada grupo faz uso dos recursos do Whatsapp, seguido, em menor quantidade, do Messenger e do Telegram. Em aulas posteriores, verificou-se a conformidade dessa preferência pelo Whatsapp com a criação de grupos de discussão contendo todos os estudantes de cada turma e sendo utilizado como principal canal de comunicação entre eles, além de servir para disseminação de informação, como avisos dos docentes quanto à realização e entrega de atividades.

Gráfico 5 - Aplicativos de mensagens instantâneas mais acessados, em \%

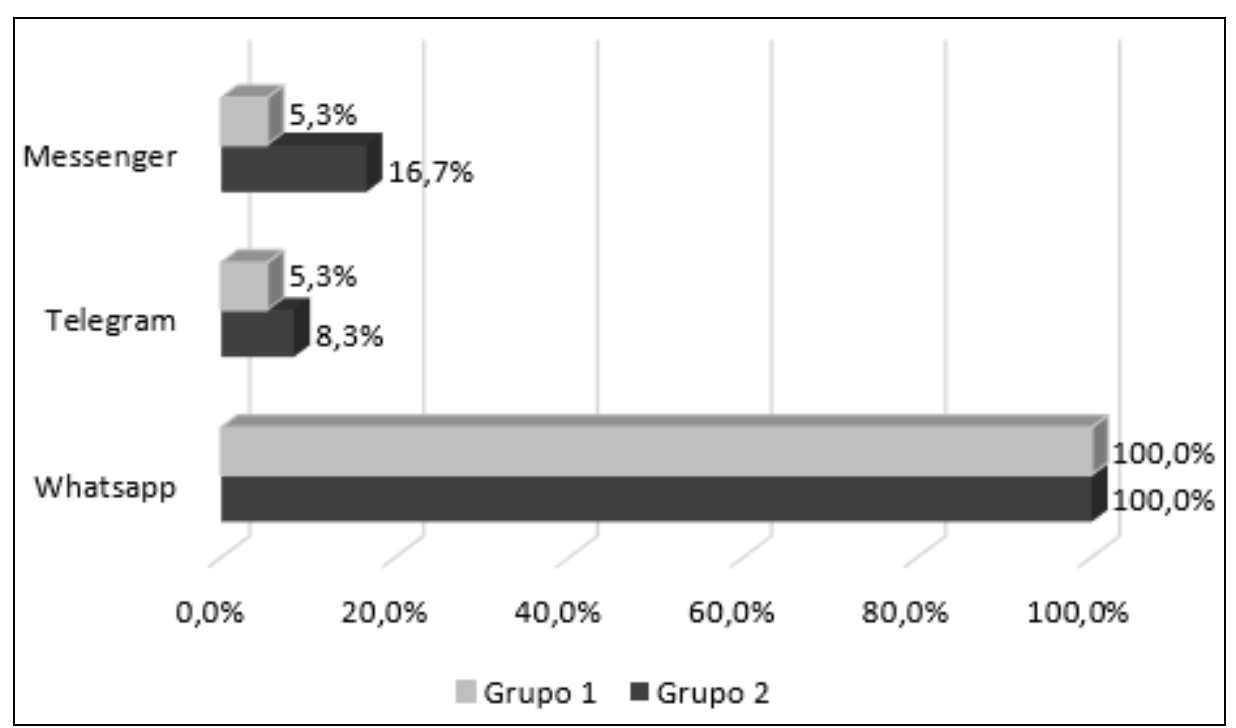

Fonte: Elaborado pelas autoras, 2019. 
Em outra questão foi abordada a utilização de aplicativos de escritório, conhecidos como Softwares de Edição disponibilizados, principalmente, nos pacotes Libre Office ${ }^{\circledR} \mathrm{e}$ Microsoft Office ${ }^{\circledR}$. As respostas, mostradas no Gráfico 6, ressaltam o emprego de editores de texto em detrimento aos softwares de planilha eletrônica e de apresentação. Há ainda aqueles usuários que desconhecem estes softwares e/ou não fazem uso. Quanto ao nível de conhecimento, foi perguntado aos participantes como consideravam sua experiência, sendo que a maioria do Grupo 1 (85,7\%) e do Grupo 2 (80\%) indicou ter um nível básico, enquanto os demais afirmaram ter nível intermediário. O nível avançado não foi apontado pelos estudantes.

Gráfico 6 - Softwares de edição utilizados, em \%

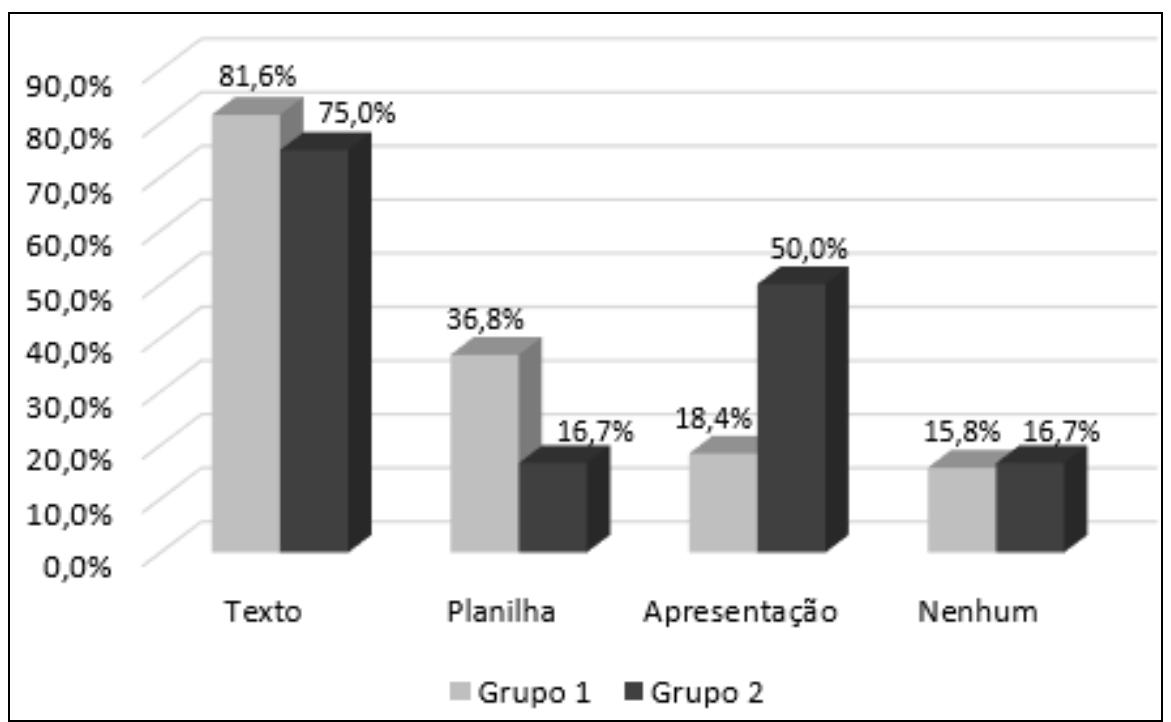

Fonte: Elaborado pelas autoras, 2019.

A única questão aberta da pesquisa buscou identificar quais temas os estudantes gostaria que fossem abordados durante a disciplina. Palavras como "word", "excel", "conhecimento" e "aprender" ou, resumidamente, "tudo que for possível” foram mencionadas pelo Grupo 1, demonstrando interesse geral em aprimorar outras habilidades. Para o Grupo 2, a frequência de "ferramentas", "forma", "escritório" e "disciplina" revela um interesse mais específico direcionado à área do curso, o que remete à análise do momento em que se encontra essa turma, após um ano e meio de ingresso no IFB, com uma visão mais orientada às necessidades de atuar no campo de trabalho e a proximidade com o término no curso. 


\section{ANÁLISE DOS RESULTADOS}

As práticas informacionais dos estudantes do PROEJA puderam ser evidenciadas durante os encontros com a docente de Informática, tendo em vista algumas ações que são comumente realizadas por estes indivíduos, como capturar uma foto com as anotações registradas no quadro branco por meio do celular e enviar para o "grupo de Whatsapp da turma" e; a pesquisa por um termo ou conceito imediatamente após ter sido mencionado durante a discussão de determinado assunto. Essas ações demonstram que um dispositivo, como o smartphone, conectado à Internet permite expandir o conhecimento dos estudantes dentro e fora do ambiente escolar e pode levá-los a fazer conexões virtuais e reais a qualquer tempo.

A utilização de ferramentas de escritório durante a disciplina mostrou que, embora os estudantes tenham afirmado que possuem computador em casa, muitos não demonstraram domínio do teclado durante a digitação de textos pelo fato, por exemplo, de não terem prática com a alternância entre letras maiúsculas e minúsculas, bem como a acentuação de palavras. Infere-se que tal dificuldade é determinada pela ausência de prática de digitação regular com o celular, o qual possui um teclado reduzido, diferenciando-se do padrão QWERT do computador desktop ou notebook, e da ausência da ferramenta de preenchimento automático para completar as palavras. Com isso, os estudantes acabam por não perceber a correta grafia das palavras, deixando essa tarefa a cargo dos aplicativos de celular.

\section{CONSIDERAÇÕES}

Em um cenário de crescente uso das mídias, como redes sociais e aplicativos de batepapo, a pesquisa revela possibilidades para a elaboração de atividades práticas que utilizem estes serviços para, por exemplo: promover a pesquisa por assuntos específicos da área do curso, discutir temas atuais e em destaque nas redes sociais, motivar a produção textual associada às aulas de língua portuguesa, criar um glossário de termos da área de Informática e associar os neologismos daqueles em língua estrangeira, entre outras.

Como sugestão para coletas futuras de dados com os estudantes do PROEJA, propõese a inclusão de questões que tratem mais especificamente das fontes de informação com as quais esse público se beneficia no seu cotidiano, tanto para realizar as pesquisas acadêmicas quanto para se manter informado das notícias. 


\section{REFERÊNCIAS}

ARAÚJO, C. A. A. Estudos de usuários da informação: comparação entre estudos de uso, de comportamento e de práticas a partir de uma pesquisa empírica. Informação em Pauta, Fortaleza, CE, v. 1, n. 1, jan./jun. 2016.

BRASIL. Decreto $\mathbf{n}^{\mathbf{0}}$ 5.840, de 13 de julho de 2006. Institui, no âmbito federal, o Programa Nacional de Integração da Educação Profissional com a Educação Básica na Modalidade de Educação de Jovens e Adultos - PROEJA, e dá outras providências. Disponível em: http://www.planalto.gov.br/ccivil_03/_ato2004-2006/2006/decreto/D5840.htm. Acesso em: 06 jan. 2019.

BRASIL. Ministério da Educação (MEC). Catálogo Nacional dos Cursos Técnicos. 2016. Disponível em: http://portal.mec.gov.br/docman/novembro-2017-pdf/77451-cnct-3a-edicaopdf-1/file. Acesso em: 06 fev. 2018.

CALVA GONZÁLEZ, Juan Jose. Investigación Bibliotecológica, Cidade do México, v. 26, n. 56, p. 7-10, 2012.

CASTELLS, M. A Sociedade em Rede. São Paulo: Paz e Terra, v. 1, 2. ed., 1999.

CGI.Br - COMITÊ GESTOR DA INTERNET NO BRASIL. TIC Domicílios 2016. Pesquisa sobre o uso das Tecnologias de Informação e Comunicação nos domicílios brasileiros - TIC Domicílios 2016. São Paulo, 2017a. Disponível em: https://www.cetic.br/media/docs/publica coes/2/TIC_DOM_2016_LivroEletronico.pdf. Acesso em: 28 jul. 2018.

DUARTE, A. B. S.; ARAÚJO, C. A. A.; PAULA, C. P. A. Práticas informacionais: desafios teóricos e empíricos de pesquisa. Informação em Pauta, Fortaleza, v. 2, número especial, p. 111-135, 2017.

FIGUEIREDO, N. M. Estudos de uso e usuários da informação. Brasília: IBICT, 1994. 154 p.

GANDRA, T. K.; DUARTE, A. B. S. Interlocuções entre a análise de domínio e os estudos de usuários da informação: contribuições para uma abordagem sociocognitiva. In: ENCONTRO NACIONAL DE PESQUISA EM CIÊNCIA DA INFORMAÇÃO, 14., 2013, Florianópolis. Anais [...] Florianópolis: ENANCIB, 2013. Disponível em: http://enancib.ibict. br/index.php/enancib/xivenancib/paper/view/4167/3290. Acesso em: 03 dez. 2018.

INSTITUTO FEDERAL DE BRASÍLIA (IFB). Plano de Curso do Técnico de Nível Médio em Administração Integrado ao Ensino Médio na modalidade PROEJA. 2016. Disponível em: http://www.ifb.edu.br/attachments/article/5913/PLANO\%20DE\%20CURSO \%20PROEJA\%20ADM\%20ATUALIZADO.pdf. Acesso em: 06 jan.2019.

INSTITUTO FEDERAL DE BRASÍLIA (IFB). IFB em Números. 2019. Disponível em: http://ifbemnumeros.ifb.edu.br/. Acesso em: 06 jan. 2019. 
KAFURE, I.; ROCHA, S.; RODRIGUES, V.; SOUZA, A.; BASTOS, K.; RAPOSO, P.; MALHEIROS, T.; BOERES, S.; FEITOSA, A. A terminologia no estudo do usuário da informação. Biblios, Brasília, n. 51, p. 1-19, 2013.

KAUARK, F. S.; MANHÃES, F. C.; MEDEIROS, C. H. M. Metodologia da pesquisa: Guia Prático. Itabuna, BA: Via Litterarum, 2010.

MACHADO, V. R. Educação básica integrada à educação profissional na modalidade de educação de jovens e adultos: uma proposta de ensino de língua portuguesa com base em projetos de letramento. In: TERRAZA, C. H. (Org.) Integrações: diálogos sobre o ensino médio. Brasília: Editora IFB, p. 37-58, 2016.

MALHEIROS, T. M.; CUNHA, M. B. As bibliotecas como facilitadoras no acesso à informação por usuários com deficiência visual. RDBCI: Revista Digital de Biblioteconomia e Ciência da Informação. Campinas, v. 16, n. 1, p. 146-170, 2018.

MARTÍN MORENO, C. Metodología de investigación en estudios de usuarios. Revista General de Información y Documentación, Brasília, v. 17, n. 2, p. 129-149, 2007.

MELO, A. P.; LOUREIRO, A. C. C. A busca pelo pensamento crítico, incentivo à pesquisa e empoderamento: contribuições da disciplina de informática na formação de jovens e adultos. In: SILVA, M. C. M.; DIAS, P. C. (Orgs.) Estudos em Educação Social: suas aplicações na Educação Profissional. Brasília: Editora IFB, p. 186-211, 2017.

PASSARELli, B.; ANGELUCI, A. C. B. Conectividade contínua e acesso móvel à informação digital. Informação \& Sociedade: Estudos, João Pessoa, v. 28, n. 2, p. 197-208, 2018.

PRENSKY, Mark. Digital Natives, Digital Immigrants. On the Horizon, Reino Unido, v. 9, n. 5, p. 1-6, 2001.

REIS, A. S.; PEDROSO, A. P. F.; CUNHA, C. S. A questão informacional e o uso de recursos tecnológicos na educação de jovens e adultos de Belo Horizonte (EJA-BH): realidade e utopia na prática docente. Ponto de Acesso, Salvador, v. 4, n. 3, p. 16-31, 2010.

SANTOS, S. K. S. L.; ROCHA, M. R. C. Interdisciplinaridade no PROEJA: informática e língua portuguesa. EJA em Debate, Florianópolis, v. 7, n. 11, p. 1-12, 2018.

SAVOLAINEN, R. Information behavior and information practice: reviewing the "umbrella concepts" of information-seeking studies. Library Quarterly, Chicago, v. 77, n. 2, p. 109$132,2007$.

SILVA, E. A.; MARCHAND, P. S. Formação Continuada: uso das TIC no processo educativo da EJA. In: BEVENUTI, J.; ARENHALDT, R.; SANTOS, S. V.; MARQUES, T. B. I. (Orgs.). Refletindo sobre PROEJA: produções de Porto Alegre. Cadernos PROEJA 11. Especialização - Rio Grande do Sul. Pelotas: Editora Universitária/UFPEL, p. 137-149, 2010. 
SOARES, Magda. Novas Práticas de Leitura e Escrita: letramento na cibercultura. Educação e Sociedade, Campinas, vol. 23, n. 81, p. 143-160, dez. 2002. Disponível em: http://www.scielo.br/pdf/es/v23n81/13935.pdf. Acesso em: 09 abr. 2018.

SOUSA, L. C. A TIC na educação: uma grande aliada no aumento da aprendizagem no Brasil. Revista Eixo, Brasília, v. 5, n. 1, p. 19-25, 2016.

VILLASEÑOR RODRÍGUEZ, I.; CALVA GONZÁLEZ, J. J. El perfil del usuario 2.0 de la información audiovisual y textual: análisis y discusión. In: CALVA GONZÁLEZ, J. J. (Org.) Usuarios 2.0 de la información audiovisual y textual, 103 p. Madrid: 2017. 